\title{
Comparative genome analysis of Pseudogymnoascus spp. reveals primarily clonal evolution with small genome fragments exchanged between lineages
}

Evgeny V Leushkin ${ }^{1,2^{*}}$, Maria D Logacheva ${ }^{1,2,3}$, Aleksey A Penin ${ }^{1,2,4}$, Roman A Sutormin ${ }^{1,5}$, Evgeny S Gerasimov ${ }^{1,4}$, Galina A Kochkina ${ }^{6}$, Natalia E Ivanushkina ${ }^{6}$, Oleg V Vasilenko ${ }^{6}$, Alexey S Kondrashov ${ }^{1,7}$ and Svetlana M Ozerskaya ${ }^{6}$

\begin{abstract}
Background: Pseudogymnoascus spp. is a wide group of fungi lineages in the family Pseudorotiaceae including an aggressive pathogen of bats $P$. destructans. Although several lineages of $P$. spp. were shown to produce ascospores in culture, the vast majority of $P$. spp. demonstrates no evidence of sexual reproduction. $P$. spp. can tolerate a wide range of different temperatures and salinities and can survive even in permafrost layer. Adaptability of $P$. spp. to different environments is accompanied by extremely variable morphology and physiology.

Results: We sequenced genotypes of 14 strains of $P$. spp., 5 of which were extracted from permafrost, 1 from a cryopeg, a layer of unfrozen ground in permafrost, and 8 from temperate surface environments. All sequenced genotypes are haploid. Nucleotide diversity among these genomes is very high, with a typical evolutionary distance at synonymous sites $d S \approx 0.5$, suggesting that the last common ancestor of these strains lived $>50$ Mya. The strains extracted from permafrost do not form a separate clade. Instead, each permafrost strain has close relatives from temperate environments.

We observed a strictly clonal population structure with no conflicting topologies for $~ 99 \%$ of genome sequences. However, there is a number of short ( 100-10,000 nt) genomic segments with the total length of $67.6 \mathrm{~Kb}$ which possess phylogenetic patterns strikingly different from the rest of the genome. The most remarkable case is a MAT-locus, which has 2 distinct alleles interspersed along the whole-genome phylogenetic tree.

Conclusions: Predominantly clonal structure of genome sequences is consistent with the observations that sexual reproduction is rare in $P$. spp. Small number of regions with noncanonical phylogenies seem to arise due to some recombination events between derived lineages of $P$. spp., with MAT-locus being transferred on multiple occasions. All sequenced strains have heterothallic configuration of MAT-locus.
\end{abstract}

Keywords: Asexual fungus, Clonality, Recombination, MAT-locus

\footnotetext{
*Correspondence: leushkin@gmail.com

${ }^{1}$ Department of Bioengineering and Bioinformatics, Lomonosov Moscow

State University, Leninskye Gory 1-73, Moscow 119992, Russia

${ }^{2}$ Institute for Information Transmission Problems of the Russian Academy of

Sciences, Moscow 127994, Russia

Full list of author information is available at the end of the article
} 


\section{Background}

Pseudogymnoascus spp. is a group of fungi species which phylogenetically belongs to the phylum Ascomycota, family Pseudeurotiaceae. Many of the P. spp. including $P$. destructants were known as Geomyces spp. until reclassification based on phylogenetic analysis conducted in [1]. Species boundaries in Pseudogymnoascus still remain uncertain [1] recalling an overall problem in fungal taxonomy [2]. P. spp were long time believed to be anamorphic based on the absence of the evidence of sexual reproduction [3-6], P. destructants was shown to spread clonaly in North America [7]. However, several homothallic lineages of $P$. spp were shown to produce ascospores in culture $[1,8]$, while $P$. destructants was proposed to have a heterothallic sexual reproduction pathway.

Morphology of $P$. spp. varies dramatically dependent on the growing conditions [9]. P. spp. are widespread in soils and can be found almost everywhere from Arctica to Antarctica [10]. P. spp. can tolerate low temperatures and high salinity, although they are not truly psychrophilic or halophilic [11-14]. P. spp. can degrade keratin and cause skin infections [15], and $P$. destructans causes white nose syndrome in bats [16].

Strictly asexual reproduction should result in clonal structure of population. However, sex is often hard to detect in experimental studies on Ascyomycota species [17]. Also many Ascomycota species are capable of parasexual process, which consists of fusion of cells followed by chromosome loss which eventually restores the normal caryotype, but does not involve meiosis. Parasexual process is often accompanied by recombination, although its rate is lower than that of meiotic recombination and it affects only short chromosome segments $[18,19]$. Horizontal gene transfer (HGT) can also occur in fungi. The most common type of HGT involves homologous recombination between genome sequences [20]. Although most of the cases reported so far involve HGT between different species [21], one can expect that within-population HGT which involves homologous recombination is even more common $[20,22]$. Thus, even if $P$. spp. truly lack meiosis, there still could be some genetic exchanges between strains in its populations.

Whole-genome analysis of $P$. spp. enables us to investigate such recombination events and detect genes associated with recombination activity. It also reveals relation between strains extracted from permafrost and temperate environments, which are considered isolated. Here, we report data on the genetic structure of $P$. spp. strains.

\section{Results}

Genome assembly, annotation, and key characteristics of P. spp. genomes

We performed whole-genome sequencing and analysis of 14 P. spp. strains.
These strains were collected from different habitats: temperate environment and Arctic active layers (contemporary samples), permafrost (age is 1.8-3.0 myr) and cryopeg, a layer of unfrozen ground in permafrost, (age is 120,000-200,000 years), and from different geographic locations (Table 1). None of the strains was seen to produce ascospores. Sequencing was performed on HiSeq2000 machine using paired-end libraries with average insert size $\sim 350 \mathrm{nt}$. The sequenced reads were assembled, independently for each individual, with SOAPdenovo (v. 1.05). Assembly statistics for each strains are listed in Table 2. Whole-genome alignments of the assembled genotypes was created with LASTZ and CLUSTAL (see Materials and Methods). Mapping reads to their assembly reveals that all studied $P$. spp. isolates are haploid.

Annotation of genomes of the sequenced strains was performed with Augustus [23] v.2.7. Number of annotated genes within a genome varies from 9516 to 12470 (Table 3). The vast majority of genes is present in all or almost all assemblies (Additional file: 1 Figure S1), e.g. out of 11305 genes in strain VKM F-3808, 8495 genes were identified in at least 10 other assemblies and 487 were not found in any other assembly. Using CEGMA

Table 1 Habitats and geography of $P$. spp.

\begin{tabular}{|c|c|c|}
\hline $\begin{array}{l}\text { Strain number } \\
\text { (VKM) }\end{array}$ & Habitat & Geography \\
\hline$F-3808$ & $\begin{array}{l}\text { Temperate } \\
\text { environment }\end{array}$ & Russia, Tverskaya oblast \\
\hline$F-3557$ & $\begin{array}{l}\text { Temperate } \\
\text { environment }\end{array}$ & Sweeden \\
\hline$F-3775$ & $\begin{array}{l}\text { Temperate } \\
\text { environment }\end{array}$ & Germany \\
\hline$F-4246$ & $\begin{array}{l}\text { Temperate } \\
\text { environment }\end{array}$ & Mongolia, Selenge Aimag \\
\hline$F-4281$ & Cryopeg & $\begin{array}{l}\text { Russia, Yakutia, Kolyma } \\
\text { lowland }\end{array}$ \\
\hline$F-4513$ & Permafrost & $\begin{array}{l}\text { Russia, Yakutia, Kolyma } \\
\text { lowland }\end{array}$ \\
\hline$F-4514$ & Permafrost & $\begin{array}{l}\text { Russia, Yakutia, Kolyma } \\
\text { lowland }\end{array}$ \\
\hline$F-4515$ & Permafrost & $\begin{array}{l}\text { Russia, Yakutia, Kolyma } \\
\text { lowland }\end{array}$ \\
\hline$F-4516$ & Permafrost & $\begin{array}{l}\text { Russia, Yakutia, Kolyma } \\
\text { lowland }\end{array}$ \\
\hline$F-4517$ & Permafrost & $\begin{array}{l}\text { Russia, Yakutia, Kolyma } \\
\text { lowland }\end{array}$ \\
\hline$F-103$ & $\begin{array}{l}\text { Temperate } \\
\text { environment }\end{array}$ & USA, New York \\
\hline$F-4518$ & Arctic active layer & $\begin{array}{l}\text { Russia, Yakutia, Kolyma } \\
\text { lowland }\end{array}$ \\
\hline$F-4519$ & Arctic active layer & $\begin{array}{l}\text { Russia, Yakutia, Kolyma } \\
\text { lowland }\end{array}$ \\
\hline$F-4520$ & Arctic active layer & $\begin{array}{l}\text { Russia, Yakutia, Kolyma } \\
\text { lowland }\end{array}$ \\
\hline
\end{tabular}


Table 2 Assembly statistics

\begin{tabular}{lllllll}
\hline Strain number (VKM) & Number of reads & Coverage & Assembly length & Average contig length & Longest contig length & N50 \\
\hline F-3808 & $23,424,660$ & 27 & $31,376,466$ & 12,801 & 126,211 & 128,114 \\
F-3557 & $10,744,922$ & 11 & $26,960,732$ & 11,950 & 67,045 \\
F-3775 & $9,492,087$ & 9 & $26,619,547$ & 5,672 & 132,394 & 24,755 \\
F-4246 & $8,947,406$ & 9 & $24,833,625$ & 10,531 & 105,778 & 2,307 \\
F-4281 & 25 & $23,704,604$ & 10,355 & 135,020 & 22,823 \\
F-4513 & $27,370,574$ & 20 & $24,207,568$ & 12,794 & 143,204 & 21,424 \\
F-4514 & $18,238,108$ & 21 & $24,946,410$ & 15,456 & 204,738 & 28,067 \\
F-4515 & $21,533,593$ & 15 & $30,802,195$ & 16,560 & 202,070 & 30,182 \\
F-4516 & $27,051,031$ & 32 & $25,236,587$ & 11,909 & 157,401 & 39,825 \\
F-4517 & $26,615,833$ & $31,131,070$ & 6,388 & 209,525 & 63,620 \\
F-103 & $26,789,498$ & 28 & $27,749,379$ & 25,982 & 183,039 \\
F-4518 & $20,880,571$ & 23 & $30,987,437$ & 11,858 & 176,316 \\
F-4519 & $17,007,142$ & 15 & $28,406,515$ & 12,744 & 138,716 \\
F-4520 & $16,072,124$ & 15 & $29,758,268$ & 9,444 & 35,172 \\
\hline
\end{tabular}

pipeline [24], we demonstrated that for all P. spp. strains except F-3775, $\geq 90 \%$ of low-copy Core Eukaryotic Genes are fully present in the assembly (Table 3 ). Considerable variation of the number of annotated genes among genomes could be due to difference in assembly quality. However, separate analysis of genes pseudogenized or deleted on specific branches of the phylogenetic tree indicates asymmetric loss of genes among P. spp. strains (Figure 1A). Strains F-4281, F-4246, and F-4513 have the lowest numbers of genes and the highest rates of gene loss (1.0-2.4 $\times 10^{-5}$ per silent nucleotide substitution), whereas strains F-4518 and F-4520 have the highest number of genes and the lowest rates of gene loss (1.4$1.5 \times 10^{-6}$ per silent nucleotide substitution) (Figure 1A). Overall we detected 282 lost genes (145 deleted and 137 pseudogenes).

The GC-content varies from $49.1 \%$ to $51.1 \%$ (Table 3 ) among the sequenced strains, with the average $50.3 \%$. More than half of the genome consists of protein-coding genes. The total length of genes varies from $16.4 \mathrm{Mb}$ to 21.8 $\mathrm{Mb}$ among the strains, and the total length of intergenic regions varies within a wider range from 7.0 Mb to12.8 Mb. Average gene lengths are 1438-1828 bp, average numbers of introns per gene are 1.75-2.48,

Table 3 The key parameters of annotated genomes of $P$. spp.

\begin{tabular}{|c|c|c|c|c|c|c|c|c|}
\hline $\begin{array}{l}\text { Strain number } \\
\text { (VKM) }\end{array}$ & GC-content & $\begin{array}{l}\text { Number } \\
\text { of genes }\end{array}$ & $\begin{array}{l}\text { Average gene } \\
\text { length (bp) }\end{array}$ & $\begin{array}{l}\text { Number of } \\
\text { introns per } \\
\text { gene }\end{array}$ & $\begin{array}{l}\text { Average intron } \\
\text { length (bp) }\end{array}$ & $\begin{array}{l}\text { Median intron } \\
\text { length (bp) }\end{array}$ & $\begin{array}{l}\text { CEGMA } \\
\text { complete }\end{array}$ & $\begin{array}{l}\text { CEGMA } \\
\text { partial }\end{array}$ \\
\hline F-3808 & $50.54 \%$ & 11,305 & 1647 & 2.19 & 108 & 60 & $92 \%$ & $97 \%$ \\
\hline$F-3557$ & $50.23 \%$ & 10,717 & 1677 & 2.12 & 106 & 59 & $90 \%$ & $96 \%$ \\
\hline F-3775 & $49.08 \%$ & 11,592 & 1448 & 1.78 & 102 & 58 & $62 \%$ & $72 \%$ \\
\hline$F-4246$ & $51.07 \%$ & 9,516 & 1724 & 1.99 & 103 & 58 & $90 \%$ & $98 \%$ \\
\hline$F-4281$ & $50.52 \%$ & 9,593 & 1727 & 2.01 & 108 & 59 & $94 \%$ & $98 \%$ \\
\hline$F-4513$ & $50.86 \%$ & 9,605 & 1747 & 2.01 & 103 & 58 & $95 \%$ & $99 \%$ \\
\hline$F-4514$ & $50.50 \%$ & 10,277 & 1747 & 2.24 & 108 & 60 & $96 \%$ & $98 \%$ \\
\hline$F-4515$ & $50.17 \%$ & 11,636 & 1783 & 2.48 & 111 & 59 & $96 \%$ & $99 \%$ \\
\hline$F-4516$ & $49.93 \%$ & 10,125 & 1799 & 2.21 & 105 & 59 & $98 \%$ & $100 \%$ \\
\hline$F-4517$ & $49.97 \%$ & 11,972 & 1629 & 1.97 & 104 & 59 & $96 \%$ & $98 \%$ \\
\hline$F-103$ & $50.31 \%$ & 10,441 & 1828 & 2.20 & 106 & 59 & $97 \%$ & $99 \%$ \\
\hline$F-4518$ & $50.02 \%$ & 12,470 & 1752 & 2.15 & 109 & 59 & $96 \%$ & $98 \%$ \\
\hline$F-4519$ & $50.12 \%$ & 11,466 & 1752 & 2.11 & 108 & 59 & $96 \%$ & $99 \%$ \\
\hline$F-4520$ & $50.26 \%$ & 12,612 & 1697 & 2.08 & 107 & 59 & $96 \%$ & $98 \%$ \\
\hline
\end{tabular}




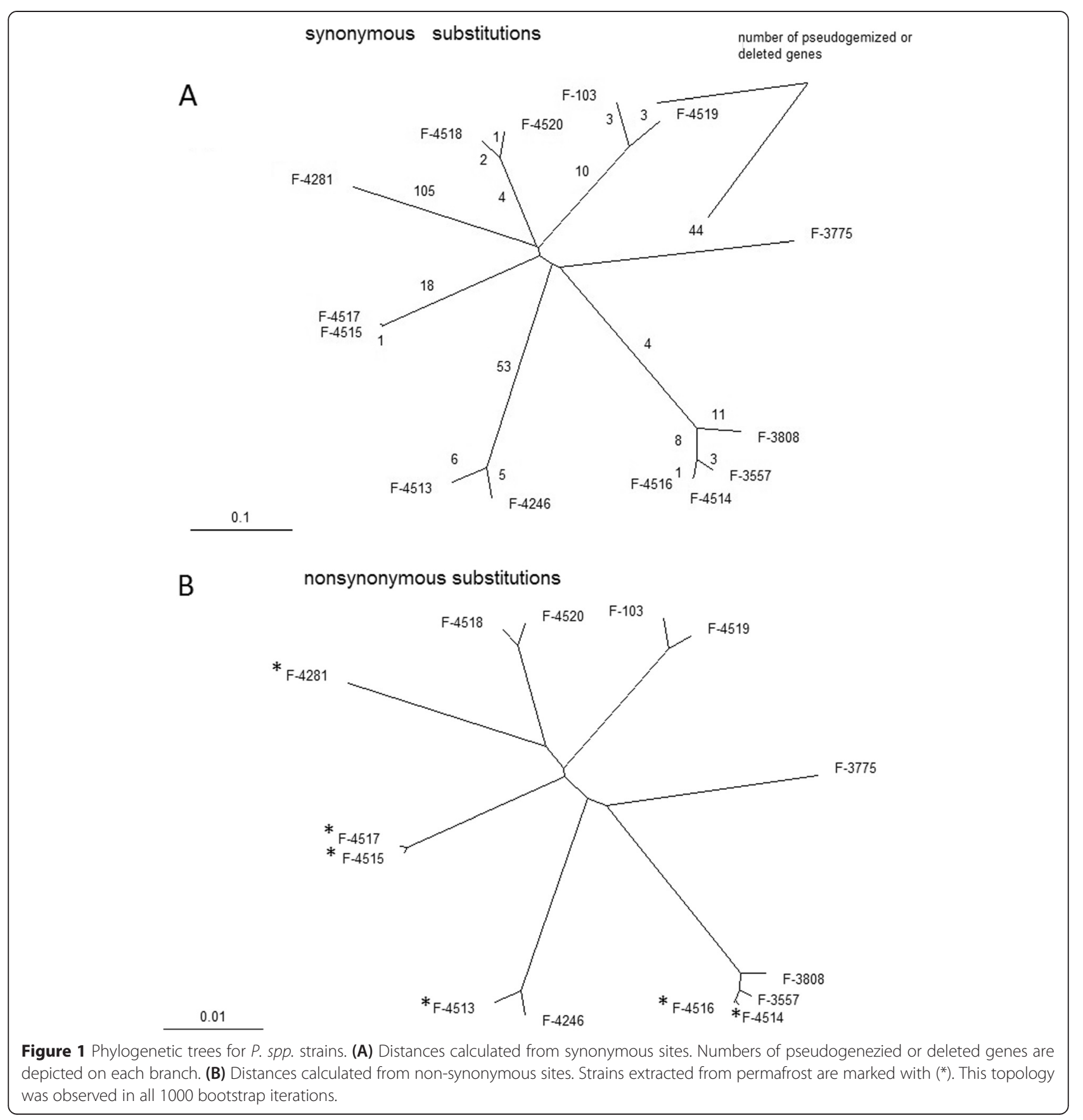

average intron lengths are 102-111 bp, median intron length is $58-60 \mathrm{bp}$ (Table 3).

We also compared sequences obtained in our study to sequences of $P$. spp. obtained previously in other studies. Genotype sequence of strain F-4281 is very similar (id = 99\%) to genotype sequence of $P$. spp. strain sequenced in [25]. We also combined our data with [1] (based on ITS region, LSU, MCM7, RPB2, and TEF1) and attributed our strains to different clades of P. spp. obtained in that study (Additional file: 1 Figure S2). Our strains correspond to 7 different clades of $P$. spp. from [25].

\section{Relationships between 14 P. spp. genotypes}

Comparison of the genomes of $P$. spp. strains reveals their very high nucleotide diversity. A typical genetic distance between two sequences at synonymous sites, $\mathrm{dS}$, is $\sim 0.5$, although some strains form compact clades (Figure 1A) and are much closer to each other. For strains from different clades, a typical distance at nonsynonymous sites $\mathrm{dN}$ is $~ 0.04$ (Figure 1B). Synteny between all genomes is extensive, and even within the most distant genome pairs over $90 \%$ of orthologous gene pairs are followed by another pair of orthologous genes (Figure 2, Additional file: 2 


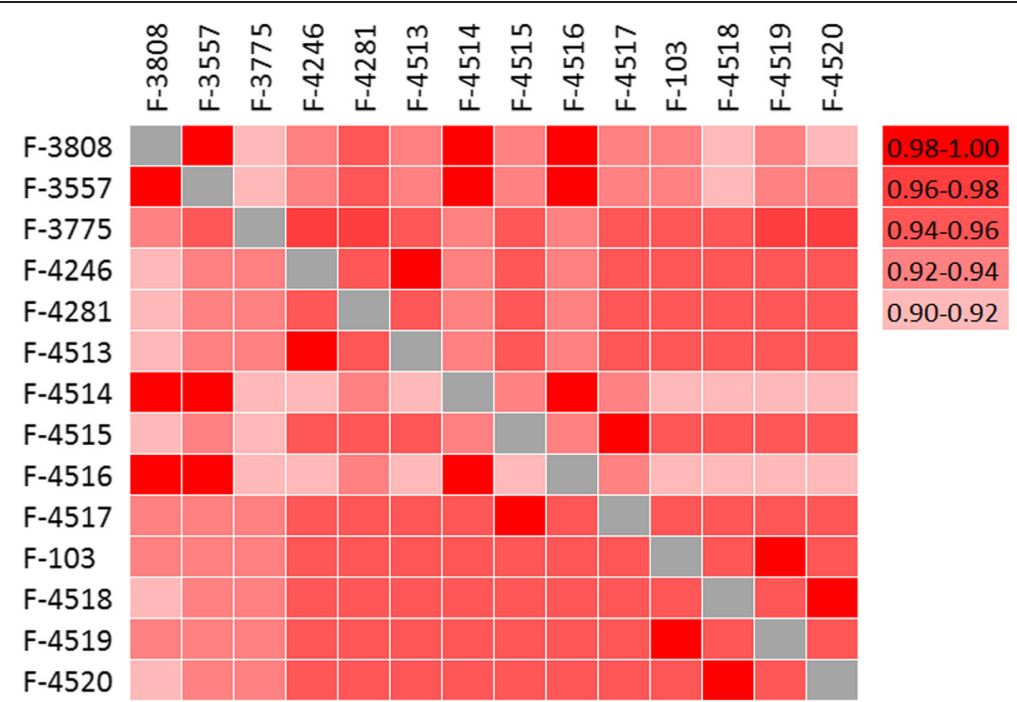

Figure 2 Genome synteny across P. spp. strains. Each square corresponds to fraction of adjacent gene pairs in strain from vertical row with orthrologs in strain from horizontal row, which are also adjacent in strain from horizontal row.

Table S1, see also Materials and methods). There are no traces of either geographical or geological structure of the global population of $P . s p p$. in the phylogenetic relationships among the analyzed genomes. Thus, these structures, if they exist, must be much younger than divergence of the ancestral lineages of these genomes.

Topology of the phylogeny shown on Figure 1 holds throughout almost the entire genome. Only $0.47 \%$, $0.31 \%, 0.05 \%, 1.27 \%$, and $0.58 \%$ of whole genome alignments do not support the 5 clades, (VKM F-3808, VKM F-3557, VKM F-4514, VKM F-4516), (VKM F-4246, VKM F-4513), (VKM F-4515, VKM F-4517), (VKM F103, VKM F-4519), and (VKM F-4518, VKM F-4520), respectively (Table 4 ). This implies that regular recombination does not take place between the P. spp. strains and supports the observations of primarily asexual reproduction in P. spp. Clade (VKM F-3808, VKM F-3557, VKM F-4514, VKM F-4516), the only clade with more than two strains, demonstrates a strong linkage disequilibrium among genotypes from the same clade (Figure 3A). No linkage disequilibrium was observed at distances over 20 nucleotides for genotypes from different clades (even at nonsynonymous sites) (Figure $3 \mathrm{BC}$ ), which is likely due to homoplasy between highly diverged $(\mathrm{d} S \sim 0.5)$ sequences and little time intervals between lineage splits. Strains VKM F-3557, VKM F-4515, VKM F-4246 were used to demonstrate relations between distant clades, however the results are similar to that observed on Figure 3BC for any combination of distant strains.

\section{Search for meiotic genes and mating pathway genes}

We searched for the genes orthologous to those which are responsible for meiosis or mating in S. cerevisiae. In P. spp. genomes we found orthologs for 17 out of 31 genes involved in different steps of meiosis in $S$. cerevisiae (Table 5), implying that 14 out of these 31 genes were lost in P. spp.. 11 out of 14 lost genes are involved in early phases of meiosis in $S$. cerevisiae: ime1 and rec12 are meiosis-inducing protein [26,27], mum2 is required for premeiotic DNA synthesis [28], red1 is required for segregation of chromosomes in meiosis I [29], zip1, zip2, zip3 and zip4 are required for initiation of chromosome synapsis [30,31]; the rest 3 of these genes,

Table 4 Number of sites according or conflicting with a clade

\begin{tabular}{|c|c|c|c|}
\hline Strains forming a clade & $\begin{array}{l}\text { Number of sites in aligment } \\
\text { centerd on a clade (nt) }\end{array}$ & Support a clade (nt) & $\begin{array}{l}\text { Conflict with a } \\
\text { clade (nt) } \\
\end{array}$ \\
\hline $\begin{array}{l}\text { (VKM F-3808, VKM F-3557, VKM F-4514, } \\
\text { VKM F-4516) }\end{array}$ & $17,307,123$ & $16,652,769$ & 81,744 \\
\hline (VKM F-4246, VKM F-4513) & $15,132,092$ & $14,901,548$ & 46,377 \\
\hline (VKM F-4515, VKM F-4517) & $15,268,980$ & $15,220,882$ & 8,318 \\
\hline (VKM F-103, VKM F-4519) & $14,941,621$ & $13,805,217$ & 189,664 \\
\hline (VKM F-4518, VKM F-4520) & $15,382,763$ & $14,838,267$ & 88,539 \\
\hline
\end{tabular}



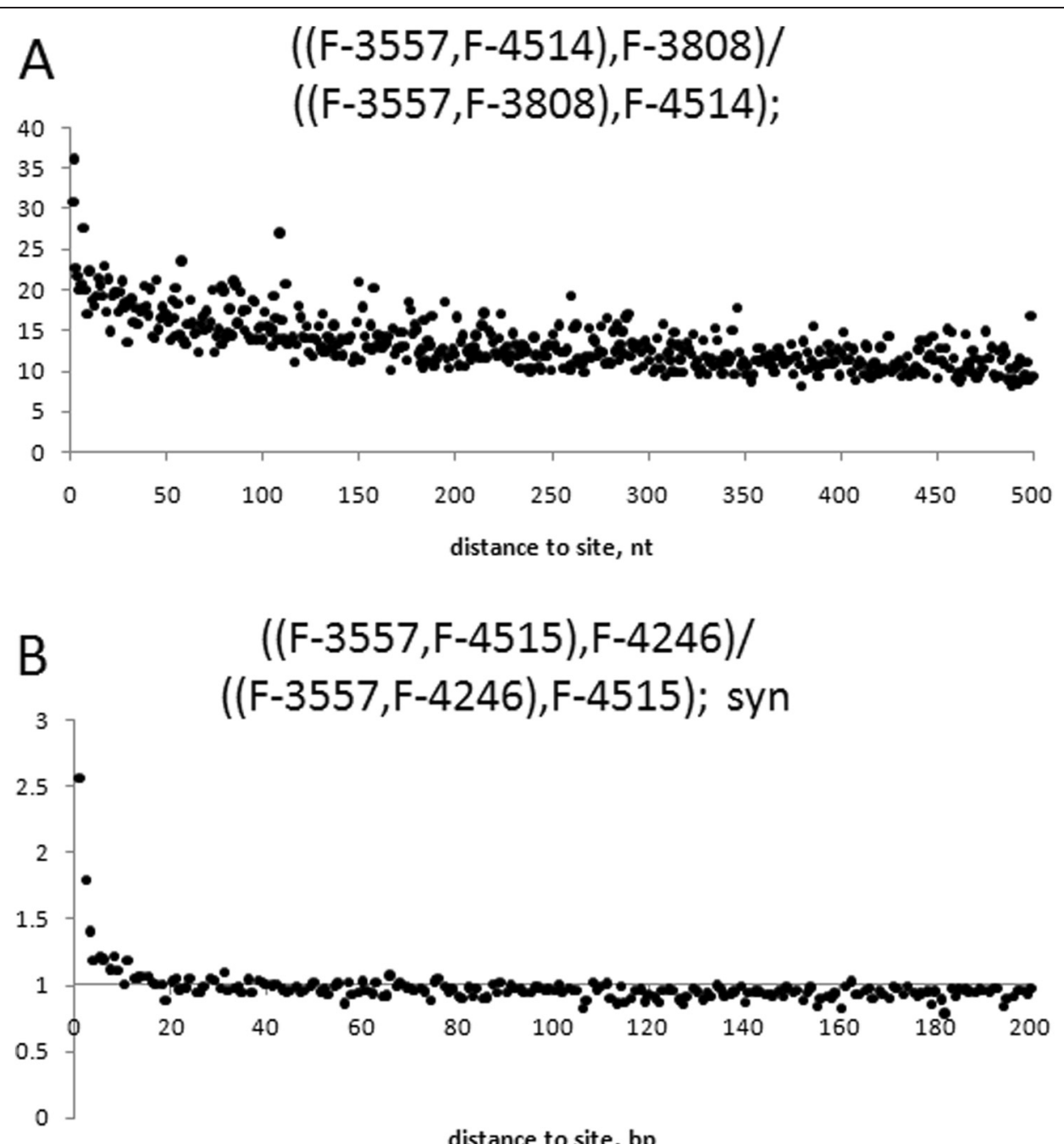

distance to site, bp

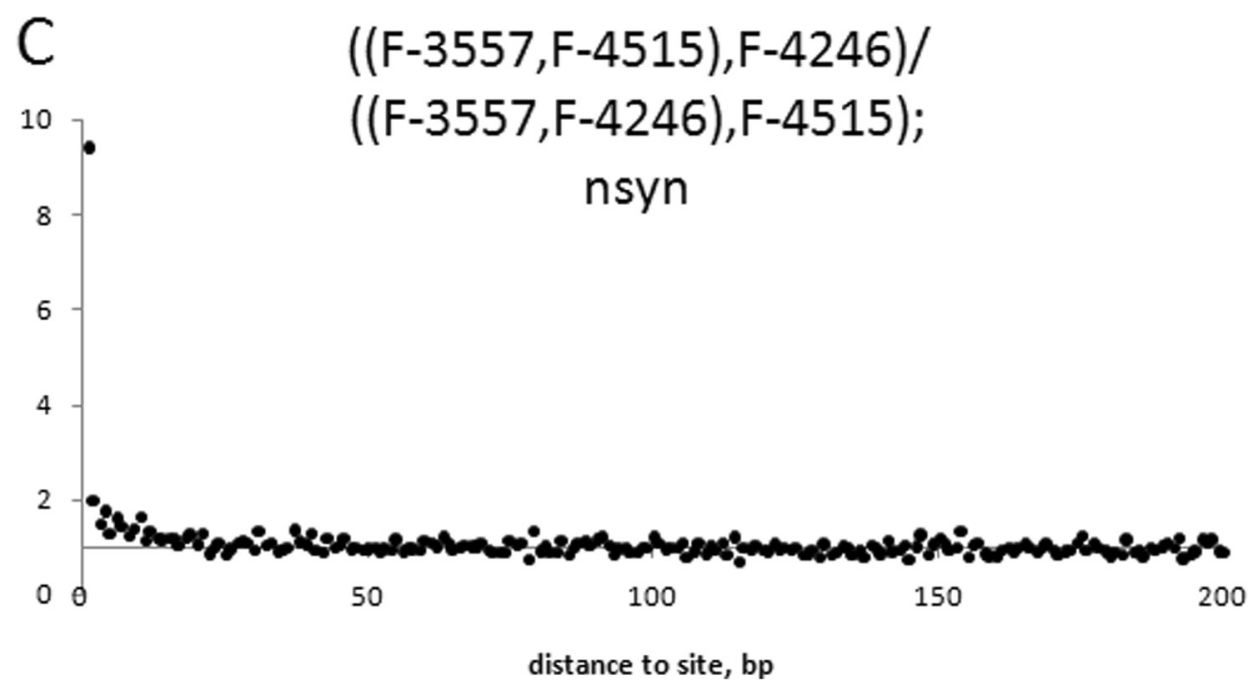

Figure $\mathbf{3}$ (See legend on next page.) 
(See figure on previous page.)

Figure $\mathbf{3}((X, Y), Z) /((X, Z), Y))$ is a ratio of the number of sites with phylogenetic configuration $((X, Y), Z)$ to the number of sites with phylogenetic configuration $((X, Z), Y)$ at distance I to a site with phylogenetic configuration $((X, Y), Z)$. (A) presents the ratio for strains from the same clade $(V K M$ F-3557, VKM F-4514, VKM F-3808), rooted by VKM F-4246. (B) and (C) presents the ratio for strains from different clades (VKM F-3557, VKM F-4515, VKM F-4246), rooted by VKM F-4519, for synonymous (B) and nonsynonymous (C) sites.

dit1, isc10 and mum3 are involved in sporulation in S. cerevisiae $[32,33]$.

In contrast to meiotic genes we observed only 1 lost gene out of 21 which are responsible for mating in S. cerevisiae (Table 5), notably all STE genes responsible for mating factor sensitivity in $S$. cerevisiae are also present in P. spp. strains [34]. A putative mating-type (MAT) locus with highly-conserved apn2 and sla2 genes was also found in P. spp. (Figure 4, Additional file: 3 Table S2).

We sequenced MAT-locus in 16 additional strains of P. spp. to study it in more detail. Two distinct idiomorphs of MAT-locus were observed: MAT1 idiomorph includes homolog of MAT1-1-1 $\alpha$-box transcription factor, homolog of MAT1-1-3 high-mobility group (HMG) transcription factor, and an unknown gene which corresponds to MAT1-1-6 in [8] (Figure 4A); MAT2 idiomorph includes MAT1-2-1 HMG-box gene and an unknown gene which corresponds to MAT1-2-5 in [8] (Figure 4B). Phylogenetic configuration at MAT-locus (Figure 5A) is strikingly different from the rest of the genome (Figure 1, Figure $5 \mathrm{~B}$ ). The boundaries of the segment with altered phylogeny reside at the ends of MAT1-1-3 and MAT1-1-1 genes for MAT1 idiomorph and MAT1-2-1 and MAT1-2-5 for MAT2 idiomorph, so that flanking regions have canonical phylogenetic configuration (Figure 5B). The last $\sim 150$ nucleotides of MAT11-1 and MAT1-2-5 are homologous to each other and unlike the rest of MAT-locus have canonical phylogenetic configuration. Multiple clades with both variants of MAT-locus and slightly variable boundaries of such segments in different strains indicate multiple recombination events within the MAT-locus (Figure 5).

No paralogs of MAT-locus were found across $P$. spp. genomes, indicating that the observed pattern could not arise due to intragenomic conversion and, instead, implying multiple intergenomic recombination events at MAT-locus. Analysis of the MAT-locus indicates that all sequenced strains are heterothallic. P. spp. strain sequenced by [25] and $P$. destructants sequenced by "Geomyces destructans Sequencing Project" (http://www.broadinstitute.org/ annotation/genome/Geomyces_destructans/MultiHome.html) also heterothallic and both have MAT1 configuration. According to [8] homothallic configuration with two idiomorphs combined also occurs in P. spp., however no homothallic strain was detected among 14 fully-sequenced strains and 16 strains with only MAT-locus sequenced suggesting that homothallism is rare in P.spp.

\section{Analysis of genomic regions with altered phylogenies}

Genotypes of VKM F-3808, VKM F-3557, and VKM F-4514 form a tight clade (all other clades have 2 or 1 genotypes) and can be used to estimate the impact of recombination on P. spp. population in more detail. For this clade we performed whole-genome search for the regions with altered phylogenetic configuration. Within the alignment of VKM F-3557, and VKM F-4514 genotypes to the rest of $12 P$. spp. genotypes, there are 77 relatively short regions, of the total length of $67.6 \mathrm{~Kb}$ and average length of $878 \mathrm{nt}$ (Figure 6A, Additional file: 4 Table S3), where phylogenetic relationships between genotypes VKM F-3808, VKM F-3557, and VKM F-4514 differ significantly (Kishino-Hasegawa test) from their canonical topology (VKM F-3808, (VKM F-3557, VKM F-4514)) (see Materials and Methods for the details of identifying these regions). Among these regions, 34 supported topology (VKM F3557, (VKM F-3808, VKM F-4514)) and 43 supported topology (VKM F-4514, (VKM F-3808, VKM F-3557)) (Additional file: 4 Table S3). Average nucleotide divergence between VKM F-3557 and VKM F-4514 in such regions is 0.115 compared to genome average 0.015 (Figure 6B, Additional file: 4 Table S3).

Figure 7 describes one of such regions. VKM F-4514 becomes an outgroup to VKM F-3557 and VKM F-3808 inside the recombined region (Figure $7 \mathrm{~B}$ ) in contrast to the flanking regions which maintain the canonical phylogenetic configuration (Figure 7AC). The genetic distances from recombined strain to strains from outside clades are not increased in this example as well as in the other regions with noncanonical phylogenetic configuration (see F-4515 vs. F-3557 and F-4515 vs. F-4514 in Additional file: 4 Table S3). Thus, such regions did not arise due to hypermutation and, instead, were likely generated through some sort of the recombination events. In one case (Figure 8), a genomic region which supported (VKM F-3557, (VKM F-3808, VKM F-4514)) topology was marked by a $5.3 \mathrm{~kb}$ inversion present in VKM F-3808 and VKM F-4514 genotypes but not in any other P. spp. genotypes. This inversion was preceded by $\sim 100$ nt noninverted segment which also supported (VKM F-3557, (VKM F-3808, VKM F-4514)) topology. Such a complex situation is very unlikely to arise through independent reversing mutations. 
Table 5 Meiotic genes and mating pathway genes in $P$. spp.

\begin{tabular}{|c|c|c|}
\hline Gene in S. cerevisiae & Ortholog in P. spp. & Function in S. cerevisiae \\
\hline$\overline{c s m 1}$ & + & Chromosome segregation \\
\hline $\operatorname{csm} 3$ & + & Chromosome segregation \\
\hline dit1 & - & Pyoverdine/dityrosine biosynthesis \\
\hline gsg1 1 & + & Late post-replication meotic role \\
\hline hop2 & + & Prevents synapsis between non-homologous chromosomes \\
\hline ime1 & - & Meiosis-inducing protein 1 \\
\hline ime2 & + & Kinase, stimulates meiotic gene expression \\
\hline isc 10 & - & Sporulation \\
\hline mck1 & + & Kinase required for ime 1 expression \\
\hline mek1 & + & A protein kinase that displays genetic interactions with RED1 and HOP1 \\
\hline mnd1 & + & Recombination and meiotic nuclear division \\
\hline msh4 & + & Required for cross-over during meiosis \\
\hline msh5 & + & MutS homolog, facilitates meiotic reciprocal recombination between homologs \\
\hline mum2 & - & Required for premeiotic DNA synthesis and sporulation \\
\hline mum3 & - & Required for premeiotic DNA synthesis and sporulation \\
\hline rad1 & + & DNA repair protein \\
\hline rad17 & + & DNA replication and repair \\
\hline rec12 & - & Meiosis induction \\
\hline red1 & - & Gene required for meiosis I \\
\hline rim4 & - & Activation of sporulation-specific genes \\
\hline smk1 & + & Sporulation specific MAP-kinase \\
\hline spol & + & Spindle body duplication \\
\hline spol1 & + & Meiosis initiation by formation of double-strand breaks in DNA \\
\hline spo14 & + & Commitment to meiosis \\
\hline spo22 & - & Chromosome segregation \\
\hline spo75 & + & Required for spore and ascus formation \\
\hline ume6 & - & Regulator of early meiotic gene expression, DNA binding protein \\
\hline zip1 & - & Meiotic chromosome synapse \\
\hline zip2 & - & Meiotic synaptoname complex \\
\hline zip3 & - & Meiotic synaptoname complex \\
\hline zip4 & - & Meiotic synaptoname complex \\
\hline akr1 & + & Required for endocytosis of pheromone receptors \\
\hline $\operatorname{cdc} 24$ & + & $\begin{array}{l}\text { Required for polarity establishment and maintenance; mutants have morphological } \\
\text { defects in bud formation and shmooing }\end{array}$ \\
\hline $\operatorname{cdc} 42$ & + & Essential for establishment and maintenance of cell polarity \\
\hline far1 & + & Inhibitor of Cdc28-Cln complex \\
\hline fus3 & + & Activates Ste12 and Far1 \\
\hline $\operatorname{lsg} 1$ & + & Required for mating and sporulation \\
\hline opy2 & + & Overproduction blocks cell cycle arrest in the presence of mating pheromone \\
\hline pea2 & - & Required for phermone-induced pointed projection formation \\
\hline sgv1 & + & Pheromone adaptation \\
\hline spa2 & + & Pheromone-induced morphogenesis and efficient mating. \\
\hline ste2 & + & Pheromone mating factor \\
\hline ste3 & + & Pheromone A receptor \\
\hline
\end{tabular}


Table 5 Meiotic genes and mating pathway genes in $\boldsymbol{P}$. spp. (Continued)

\begin{tabular}{lll}
\hline ste4 & + & Pheromone signal transduction \\
ste6 & + & ABC-type multidrug transport system \\
ste7 & + & Pheromone signal transduction \\
ste11 & + & Ser/Thr protein kinase; pheromone signal transduction \\
ste12 & + & Activates genes involved in mating or pseudohyphal/invasive growth pathways \\
ste13 & + & Peptidase,mating factor processing \\
ste18 & + & Signal transduction via G-protein-coupled receptors \\
ste20 & + & Activates transcription of FUS1 in the absence of mating pheromone \\
ste50 & + & Essential for activation of conjugation \\
\hline
\end{tabular}

Sequence reads mapped back to assemblies ensure that regions with altered phylogenetic topologies could not be assembly artifacts as reads map normally on such regions and on their boundaries, with average coverage for this regions being the same to the rest of the genome. We considered a possibility of the intragenomic nonallelelic recombination. For 3 of the 77 regions we identified paralogs inside $P$. spp. using BLAST against the entire genome. However, none of these 3 paralogs could explain the pattern we observed.

The most plausible explanation for the regions with altered topology is the weak recombination activity between the distant $P$. spp. lineages. In the first example (Figure 7), VKM F-4514 likely recombined with some genotype outside of (VKM F-3808, (VKM F-3557, VKM $\mathrm{F}-4514)$ ) clade, in the second example the inversion took place before the (VKM F-3808, (VKM F-3557, VKM F4514)) branching, but was eventually eliminated in VKM F-3557 by recombination with some distant genotype (Figure 8).

Exon sequences comprise $50.1 \%$ of the P. spp. genome, but only $11,345 \mathrm{nt}$ in 23 regions out of the total 67,577 nt in 77 recombination regions (16.8\%) overlap with exon sequences. The lack of coding sequences in recombination regions is likely due to a negative selection on high-distant recombination events at coding sequences.

\section{Discussion and conclusions}

We sequenced and independently assembled genotypes of 14 haploid P. spp. strains. Thus, we did not perform standard genotyping procedures including read mapping and SNP calling but, instead, aligned the contigs which were obtained independently. We believe this method to be preferable to read mapping, because longer sequences are aligned and more robust alignments are obtained. Longer sequences are particularly important in case of high nucleotide diversity within the aligned genotypes.

Genome comparison of the sequenced strains reveals predominantly clonal structure of $P$. spp. lineages (Figure 3A, Table 4) which is consistent with the multiple observations of asexual-only reproduction of $P$. spp. strains [1,3-6]. The sequenced genomes are also very diverse with typical distance between strains from different clades $\mathrm{d} S \approx 0.5$. Assuming that $P . s p p$. produce no more than 10 generation per year [9] and mutation rate is less than $10^{-8}$ per nucleotide per generation (similar to other $S$. cerevisiae $[35,36]$ ), we can estimate that the last common ancestor of $P$. spp. lived more than 50 Mya. However, the strains are still very similar in functional sites as $\mathrm{dN}$ between distant lineages is $\sim 0.04$, synteny of genes is $>0.9$ between different clades (Figure 2 ).

Complete absence of genetic exchanges between strains would lead to a strict clonality of the population. However, there are evidences of recombination within a number of

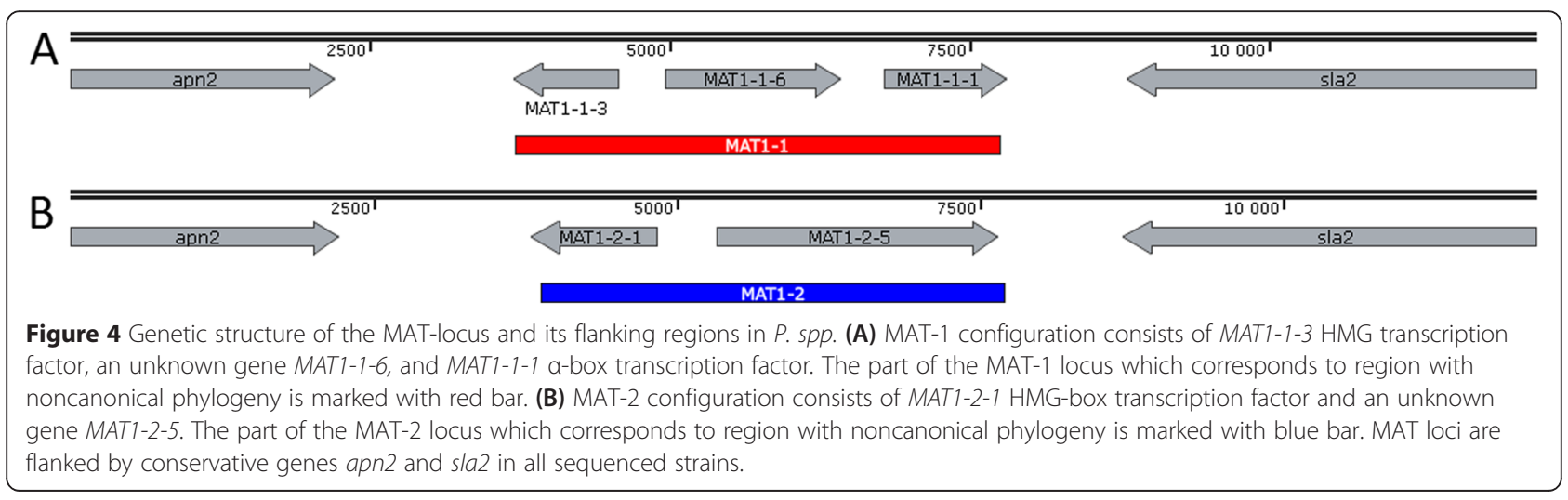



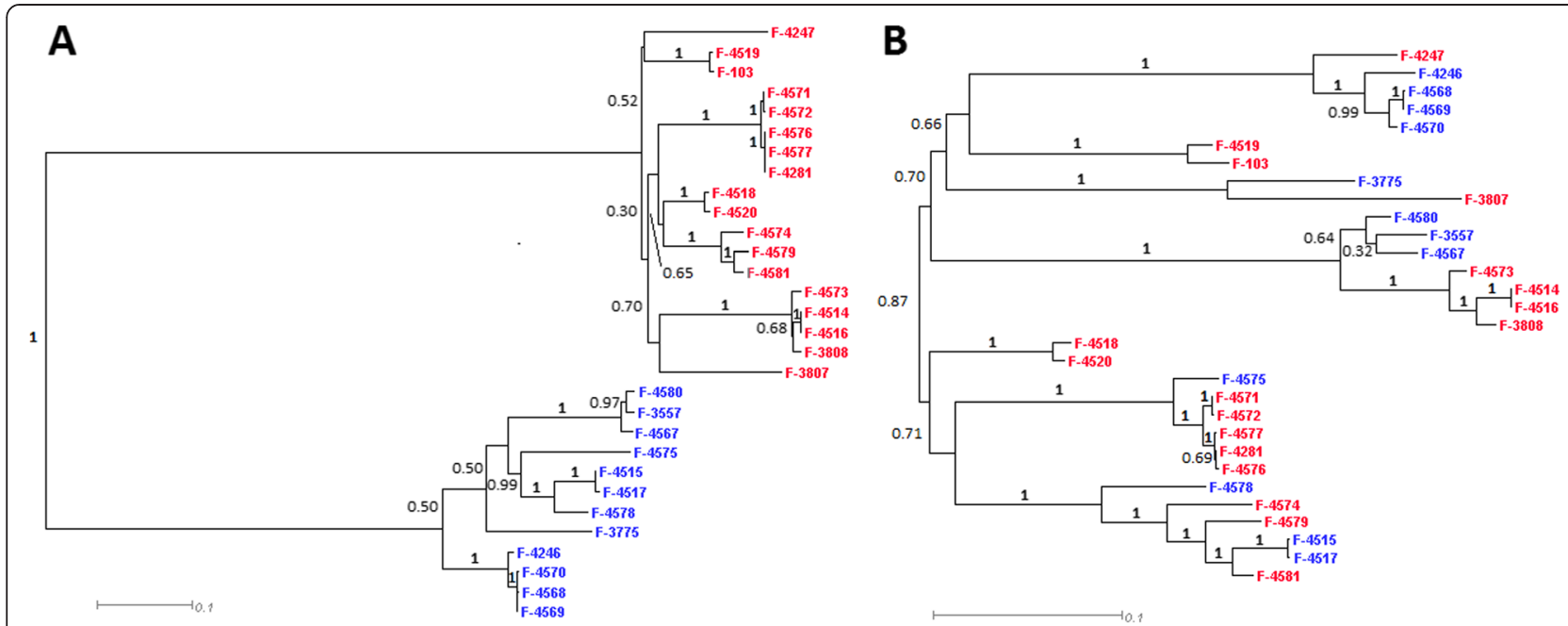

Figure 5 Phylogenetic configuration inside MAT-locus (A) compared to flanking regions (B). Strains with MAT-1 locus are marked with red, strains with MAT-2 locus are marked in blue. Bootstrap values calculated from 1000 bootstrap iterations.

genes in anamorphic Candida albicans and Aspergillus fumigatus $[37,38]$. We also observed such evidence in $P$. spp. Phylogenetic structure of MAT-locus and other regions with noncanonical topology indicates the exchange of this genome fragments between $P$. spp. lineages (Figures 4, 5, 6, 7 and 8, Additional file: 4 Table S3). Recombination rate estimated from these regions is low: 1 recombination event per $\sim 2500$ single-nucleotide substitutions at synonymous sites, and only short genome regions are affected (average length is $878 \mathrm{nt}$ ) (Figure 6). However, it is enough to cover an entire genome for a period of time passed since last common ancestor of P. spp. lineages, and thus, also contributed to the loss of linkage disequilibrium (Figure 3).
As in an asexual fungi Candida glabarta [39,40], in P. spp. we observed MAT locus and other genes responsible for mating and meiosis in $S$. cerevisiae (Table 5, S2, Figure 4). Interestingly, MAT locus in $P$. $s p p$. has phylogenetic configuration very different from the rest of the genome, indicating multiple transmissions between distant lineages at MAT locus. However, in both Candida glabarta and in vast majority of $P$. spp. sexual reproduction has never been observed, suggesting that either sexual processes are extremely rare, and thus are hard to detect, but are still important in these species, or that these genes have some functions other than sexual reproduction. Evidence of recombination at MAT locus and in other genome regions could

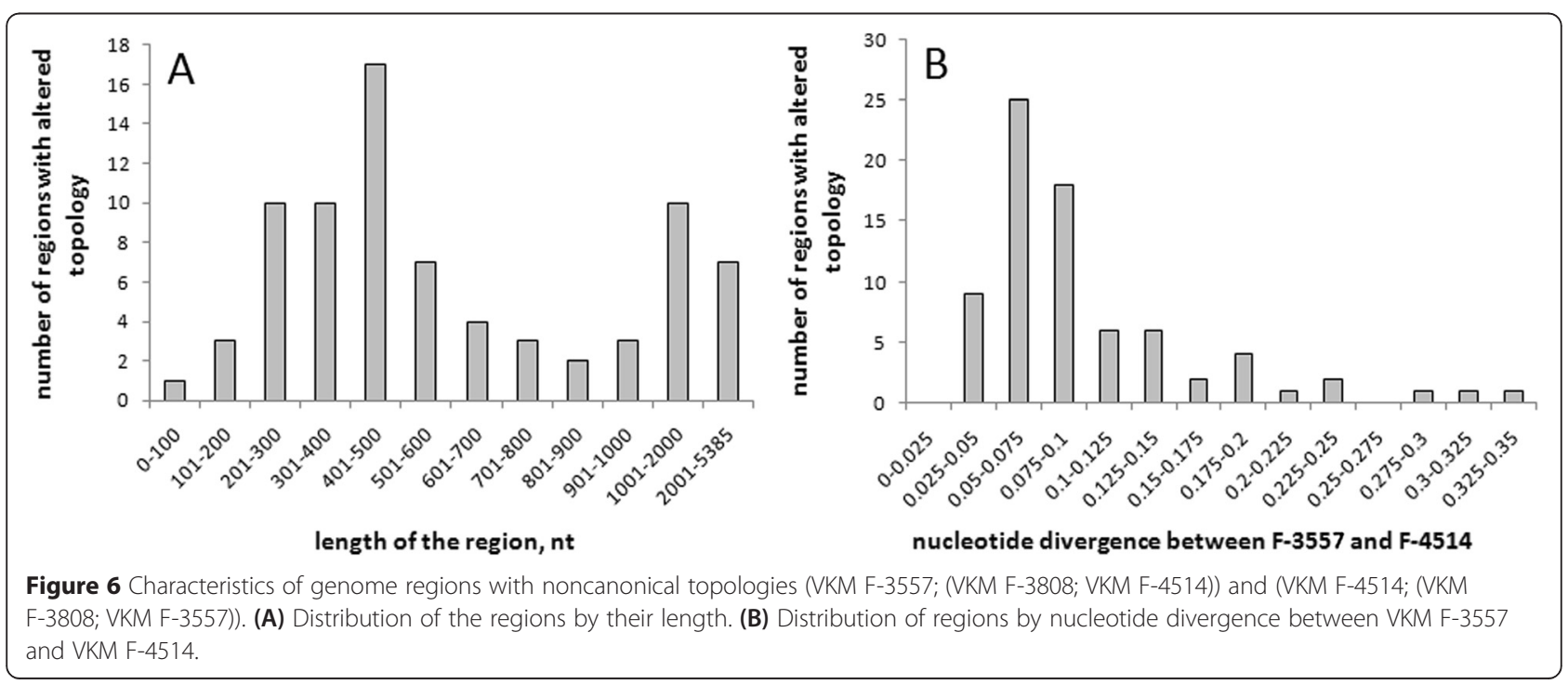




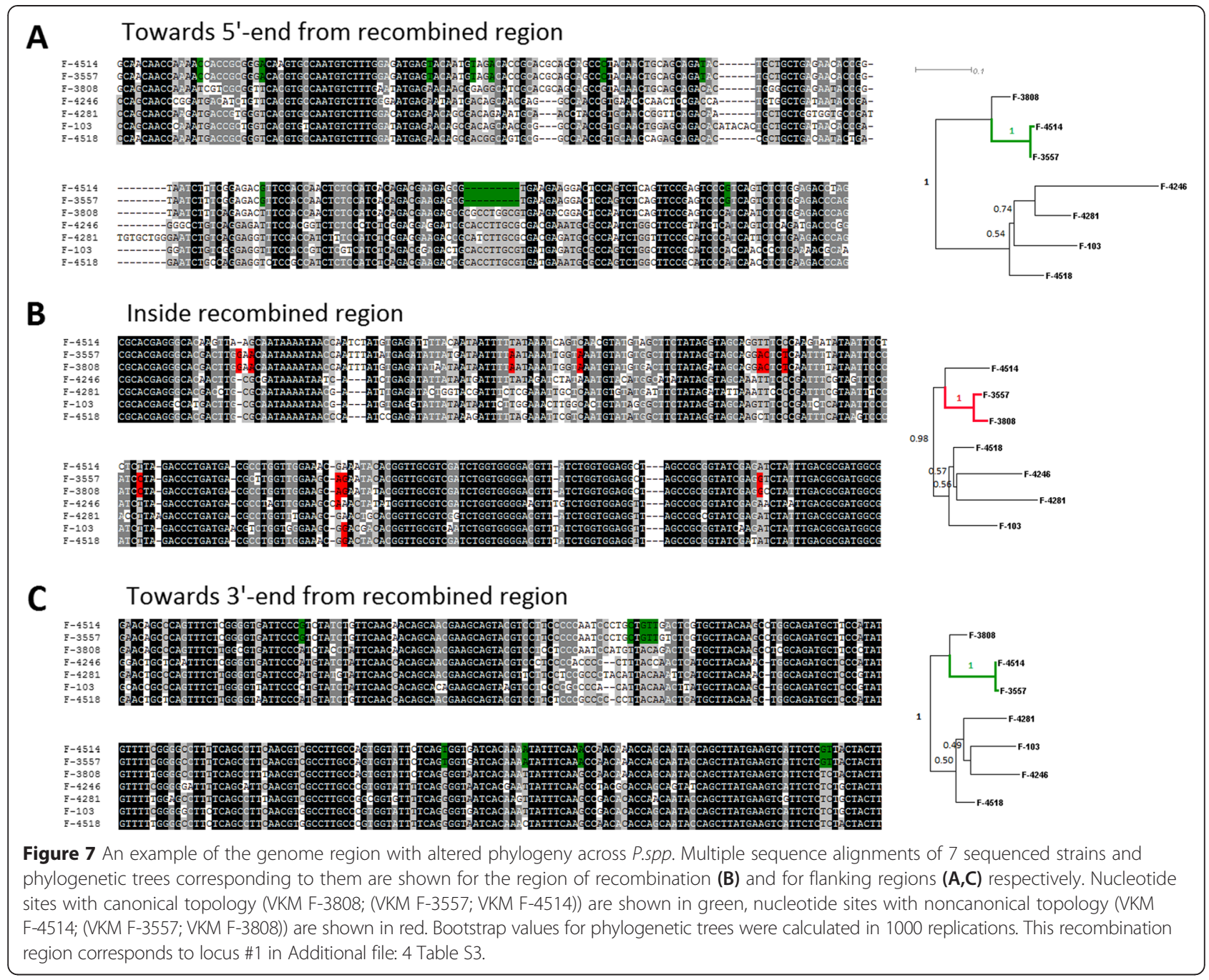

also indicate parasexual activity which is known to be a substitute of sex for many Ascomycota [19]. The other explanation could be horizontal gene transfer (HGT) across P. spp. HGT better fits the pattern observed for MAT-locus phylogeny and could indicate presence of a vector which carries and transmits MAT-locus across the population.

There are many economically significant species among Ascomycota, including aggressive pathogens of plants and animals. Recently $P$. destructans was shown to spread rapidly in North America and decimate bats populations $[7,16]$. However, population genetics and evolution of Ascomycota species remain poorly understood due to low number of whole-genome data. Our analysis reveals predominantly clonal evolution of $P$. spp. lineages. But despite a very long time passed since their last common ancestor, these strains still have very similar morphological traits and evidently occupy the same ecological niche. Indeed, strains VKM F-4513, VKM F4514 and VKM F-4517, which belong to 3 distant clades
(Figure 1), were all extracted from the permafrost samples of the same age (1.8-3.0 Myr) where no other organism could survive. Furthermore, sequenced genomes indicate some sort of genetic recombination between diverged lineages. Therefore we believe that $P$. spp. should be treated as the entity of lineages interacting with each other rather than an ensemble of independent species. This approach could also be useful in understanding evolution of the other Ascomycota species with little or unknown sexual reproduction.

\section{Methods}

Extraction and cultivation of samples from permafrost Methods of sampling, storage, transportation and control were chosen, and specialized tests were performed, to make sure that the microorganisms found in samples were indigenous and not contaminants. The cores (diameter 5-10 cm, length $15-30 \mathrm{~cm}$ ) were collected using a dry drilling technique developed specifically for microbiological studies of permafrost $[41,42]$. The dry 

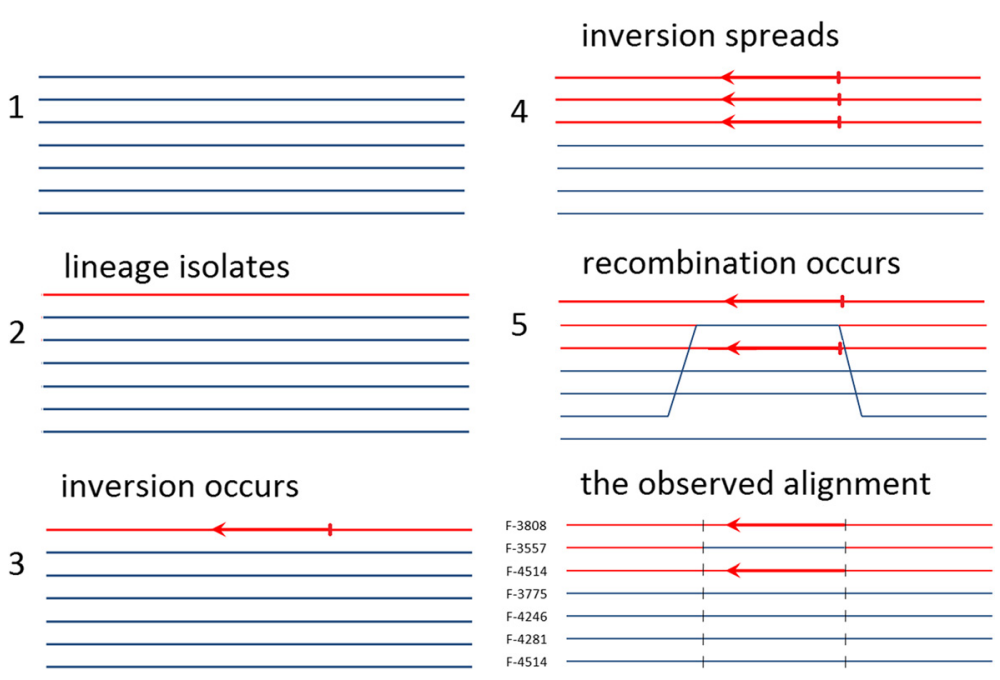

Figure 8 Evolutionary scenario which explains the observed alignment. Strains F-3808, F-3557, and F-4514 from the same clade are shown as red opposed to all other strains shown as blue. The inverted segment is marked with arrow. Region with noncanonical phylogenetic configuration is marked with black lines. The observed alignment has (VKM F-3557, (VKM F-3808, VKM F-4514)) configuration inside recombination region (marked with short black lines) and (VKM F-3808, (VKM F-3557, VKM F-4514)) canonical configuration in flanking regions. This recombination region corresponds to locus \#77 (inversion) in Additional file: 4 Table S3.

drilling and sampling prevent down-hole contamination caused by drilling fluids. The sampling is achieved by dry shaving of the core back to native ice-cemented sediment. Possible contamination during the drilling was monitored by several tests. Previous studies have employed fluidless drilling techniques combined with an exogenous bacterial tracer such as a pure culture of Serratia marcescens. In tests using the isolation techniques, S. marcescens bacteria were found only on the surface of the frozen sample, never inside the frozen cores [42].

To recover fungi, 0.5 -g portions of a core sample were placed in test tubes with $5 \mathrm{ml}$ of water heated to room temperature $\left(20^{\circ} \mathrm{C}\right)$, as well as to 35 and $52^{\circ} \mathrm{C}$. Following one minute, the suspension was shaken at room temperature for $10 \mathrm{~min}$. The tenfold dilutions of this suspension were inoculated, in triplicate, on Czapek agar $(\mathrm{Cz})$, Malt Agar (MA), Starch ammonium agar (SAA) to which lactic acid was added at a concentration of $4 \mathrm{ml} / 1$ to suppress the unwanted growth of bacterial cells. The inoculated plates were incubated at 4 and $25^{\circ} \mathrm{C}$. The grown colonies were examined and enumerated on the 21st and 30th days, respectively [43].

\section{Genome sequencing}

Before DNA extraction, all samples were grown on Malt Agar for 10 days. Total genomic DNA was extracted using modified CTAB-method [44]. To construct the libraries for whole genome sequencing DNA was processed as described in the TruSeq DNA Sample Preparation Guide (Illumina). Libraries with average length of $350 \mathrm{bp}$ were selected for sequencing. Libraries were quantified using fluorimetry with Qubit (Invitrogen, USA) and real-time PCR and diluted up to final concentration of $8 \mathrm{pM}$. Diluted libraries were clustered on a paired-end flowcell using cBot instrument and sequenced in 101 cycles using HiSeq2000 sequencer with TruSeq SBS Kit v3-HS (Illumina, USA). After trimming of adapter-derived and low (Q-score below 30) quality sequences reads were assembled using SOAP de novo assembler application (k-mer size 57). GapCloser for SOAP de novo was used to determine sequences of the gaps in scaffolds [45].

\section{RNA sequencing}

RNA-seq was performed for strains F-3808 and F-4515 grown in control conditions (malt agar, temperature 25 C) and under low temperature and high salinity (). Prior to RNA extraction, samples were collected in RNAlater solution (Ambion, USA), then homogenized using liquid nitrogen. Extraction was carried out using RNeasy Mini Kit (Qiagen, Germany) following manufacturer's instruction. The only modification was the addition of $10 \%$ Plant RNA Isolation Aid (Ambion, USA) to the lysis buffer. RNA quality was assessed using capillary electrophoresis on Bioanalyzer 2100 (Agilent, USA), only RNA with integrity number (RIN, [46]) greater or equal to 8 were taken for library preparation. For library preparation, TruSeq RNA Sample Prep Kit v2 (Illumina, USA) was used following manufacturer's instructions. After preparation libraries were quantified using Qubit fluorometer and quantitative PCR and sequenced on HiSeq2000 with read length 51 nucleotide. 


\section{MAT locus sequencing}

MAT locus was amplified using primers Geo-MAT1-2-F (5' -ATG GCT CAA AGC ACR TTG CAR GGC TTC-3') and Geo-MAT1-2-R (5'-CTT CTT TAT CTG GAC GTC ACT TCT CAC A-3') that encompass the region between genes sla 2 and $a p n 2$. PCR products were run on agarose gel and bands between 3 and $9 \mathrm{~Kb}$ were cut and purified. Libraries were prepared using Nextera XT DNA sample prep kit (Illumina, USA) and sequenced using Miseq sequencer with read length equal to 250 from each end. Libraries were $200-800$ bp in length.

\section{Genome annotation}

Gene predictions for 14 P. spp. strains were done as described further. Each genotype assembly file was masked using RepeatMasker 3.3.0. To find exons and introns, RNAseq data we had for strains F-3808 and F-4515 were mapped on the masked scaffolds of each strain using Tophat2 [47] (version 2.0.8) and the results were used to generate intron hints for AUGUSTUS gene predictor (with bam2hits and filterBam programs from AUGUSTUS pipeline, included in distributive, and samtools package for sorting and filtering). AUGUSTUS extrinsic.cfg file was adjusted for considering information about potential intron boundaries from RNAseq data (larger bonus for intron confirmed by RNA mapping, tiny penalty if not). Final gene prediction was done by AUGUSTUS [23] (version 2.7.) with intron hints and species parameter was set to "botrytis_cinerea".

\section{Whole genome alignment}

Whole-genome alignment of the assembled contigs was performed in 2 steps. First, we used LASTZ [48], the program which identifies the regions of local similarity, to match the contigs from different samples. Single_cov2 from TBA package [49] was used to filter out the lower-scored alignments in regions with more than one significant alignment. Then, to increase the length of the alignment blocks, we performed global alignment of contig groups obtained on stage 1 using CLUSTAL [50]. For the analysis of the genomic regions with the conflicting phylogenetic configuration we only used the alignment blocks of length $>20 \mathrm{kbp}$. The entire length of such blocks is $5.6 \mathrm{Mbp}$.

\section{Identifying regions with noncanonical phylogeny}

We considered a nucleotide site to support phylogenetic configuration (strain A, (strain B, strain C)), if nucleotides in strain $B$ and strain $C$ are identical and distinct from nucleotide in strain $\mathrm{A}$, also we required nucleotide in strain A to be carried by at least 6 of the rest 11 sequenced G. spp. strains. Phylogenetic configuration (VKM F-3808, (VKM F-3557, VKM F-4514)) was name canonical as it stands for the vast majority of the genome, whereas phylogenetic configuration (VKM F-3557, (VKM F-3808, VKM F-4514)) and (VKM F-4514, (VKM F-3808, VKM F3557) were named non-canonical. The nucleotide frequency of sites with noncanonical phylogenetic configuration is 0.002 .

We considered a window of length 200 nt to have a noncanonical phylogenetic configuration, if the number of nucleotide sites supporting a noncanonical phylogenetic configuration exceeds the number of sites with canonical phylogenetic configuration by at least 8 nucleotides. The threshold of 8 guaranties that less than 0.01 such windows would be found at random. The overlapping windows were combined into the resulting regions with the boundaries set at nucleotide sites supporting noncanonical phylogenetic configuration. PAML implementation of Kishino-Hasegawa test was run to compare phylogenetic configurations and calculate bootstrap values [51], pRELL threshold was set at 0.95 .

To ensure the regions with altered phylogenetic configuration are not assembly artifacts, we mapped the original sequence reads using bwa [52] program on the regions with noncanonical phylogenetic configuration, overlapping the boundaries of the region to ensure that these region are not the assembly artifacts. Regions with noncanonical phylogenetic configuration show coverage similar to the rest of the genome.

\section{Calculating phylogenetic distances, number of gene losses and synteny}

To identify gene orthologs we searched bidirectional best hits for each pair of $P$. spp. strains. We obtained 7524 groups of homologous genes, which are present in each of these 14 strains. Then, each group of homologous genes was aligned with MACSE [53]. Finally, the concatenate of alignments was used to calculate synonymous and nonsynonymous distances with codeml program from PAMLpackage. Only codon columns present in all 14 strains were used in the analysis. Dendroscope (v. 3.2.10) [54] was used for visualizations of phylogenies. We evaluate number of genes lost on each branch from sets of orthologs which have no blast hits to exon sequences in certain lineages. The lost gene is considered pseudogene if the significant blast hit to genome is observed but gene structure is disrupted, the gene is considered deleted if there is no significant blast hit to genome.

Gene orthologs were also used to estimate synteny across P. spp. strains. The pair of two orthologous genes was considered syntenic if those genes were adjacent in each strain. The pair of two orthologous genes where genes were adjacent only in one strain was considered nonsyntenic. Total numbers of syntenic orthologous pairs out of all orthologous pairs are shown in Additional file: 2 Table S1. 


\section{Data access}

Raw sequence reads, genotypes assembly and annotation for $14 P . s p p$. strains are available in the Genbank under BioProject accession number PRJNA216963.

\section{Additional files}

\begin{abstract}
Additional file 1: Figure S1. Distribution of VKM F-3808 genes by the number of $P$. spp. genome assemblies containing them. Figure $\mathbf{S 2}$. Phylogenetic relations between Pseudogymnoascus spp. VKM strains sequenced in this study and P. spp. strains from Minnis et al. [1] obtained from multuple sequene aligment of TEF1 gene.
\end{abstract}

Additional file 2: Tables S1. Numbers of pairs of adjacent genes in strain A with orthologs in strain B, and numbers of such pairs which are also adjacent in strain B (data are also presented on Figure 2 in main text).

Additional file 3: Table S2. MAT-locus coordinates in genomes of P. spp strains.

Additional file 4: Table S3. Genome regions with alterered topology.

\section{Competing interests}

Authors declare that they have no competing interests.

\section{Authors' contribution}

EVL carried out computational analysis, coordinated the study and prepared the manuscript, MDL participated in construction and sequencing of DNA libraries, participated in coordination of the study and contributed to manuscript preparation, AAP participated in construction and sequencing of DNA libraries, RAS and ESG participated in genome annotation, GAK, NEI and OW participated in extraction and cultivation of samples, ASK participated in design and coordination of the study and contributed to manuscript preparation, SMO conceived the study, participated in extraction and cultivation of samples and manuscript preparation. All authors read and approved the final manuscript.

\section{Acknowledgments}

This study was supported by Ministry of Education and Science of the Russian Federation grants №11.G34.31.0008 and 8814, by the Russian Foundation for Basic Research (grant no. 13-04-02082A), and by the Molecular and Cellular Biology Program of the Russian Academy of Sciences.

\section{Author details}

'Department of Bioengineering and Bioinformatics, Lomonosov Moscow State University, Leninskye Gory 1-73, Moscow 119992, Russia. ${ }^{2}$ Institute for Information Transmission Problems of the Russian Academy of Sciences, Moscow 127994, Russia. ${ }^{3}$ A.N. Belozersky Institute of Physico-Chemical Biology, Lomonosov Moscow State University, Moscow, Russia. ${ }^{4}$ Department of Biology, Lomonosov Moscow State University, Moscow 119992, Russia. ${ }^{5}$ Lawrence Berkeley National Laboratory, Berkeley 94710CA, USA. ${ }^{6}$ G.K.Skryabin Institute of Biochemistry and Physiology of Microorganisms RAS, Pushchino 142290, Russia. ${ }^{7}$ Department of Ecology and Evolutionary Biology, University of Michigan, Ann Arbor, MI 48109, USA.

Received: 16 December 2014 Accepted: 23 April 2015 Published online: 21 May 2015

\section{References}

1. Minnis AM, Lindner DL. Phylogenetic evaluation of Geomyces and allies reveals no close relatives of Pseudogymnoascus destructans, comb. nov., in bat hibernacula of eastern North America. Fungal Biol. 2013;117:638-49.

2. Hibbett DS, Taylor JW. Fungal systematics: is a new age of enlightenment at hand? Nat Rev Microbiol. 2013;11:129-33.

3. Hoog GSD: Atlas of Clinical Fungi, Second Edition. Amer Society for Microbiology; Utrecht, The Netherlands 2000

4. Sigler L, Lumley TC, Currah RS. New species and records of saprophytic ascomycetes (Myxotrichaceae) from decaying logs in the boreal forest. Mycoscience. 2000;41:495-502.
5. Kirk PM, Cannon PF, Minter DW, Stalpers JA: Dictionary of the Fungi. CAB International Publisher location: Wallingford, UK 2008

6. Hayes MA. The Geomyces fungi: ecology and distribution. Bioscience. 2012:62:819-23.

7. Ren P, Haman KH, Last LA, Rajkumar SS, Keel MK, Chaturvedi V. Clonal spread of Geomyces destructans among bats, Midwestern and Southern United States. Emerg Infect Dis. 2012;18:883-5.

8. Palmer JM, Kubatova A, Novakova A, Minnis AM, Kolarik M, Lindner DL. Molecular characterization of a heterothallic mating system in Pseudogymnoascus destructans, the Fungus causing white-nose syndrome of bats. G3 Bethesda Md. 2014;4:1755-63.

9. Kochkina GA, Ivanushkina NE, Akimov VN, GilichinskiI DA. Ozerskaia SM: [Halo- and psychrotolerant Geomyces fungi from arctic cryopegs and marine deposits]. Mikrobiologiia. 2007;76:39-47.

10. Marshall WA. Aerial transport of Keratinaceous substrate and distribution of the fungus Geomyces pannorum in antarctic soils. Microb Ecol. 1998:36:212-9.

11. Poole NJ, Price PC. The occurrence of Chrysosporium pannorum in soils receiving incremental cellulose. Soil Biol Biochem. 1971;3:161-6.

12. Lowry PD, Gill CO. Temperature and water activity minima for growth of spoilage moulds from meat. J Appl Bacteriol. 1984;56:193-9.

13. Robinson $\mathrm{CH}$. Cold adaptation in arctic and antarctic fungi. New Phytol. 2001;151:341-53.

14. Ozerskaya SM, Ivanushkina NE, Kochkina GA, Fattakhova RN, Gilichinsky DA. Mycelial fungi in cryopegs. Int J Astrobiol. 2004;3:327-31.

15. Gianni C, Caretta G, Romano C. Skin infection due to Geomyces pannorum var. pannorum. Mycoses. 2003;46:430-2.

16. Gargas A, Trest MT, Christensen M, Volk TJ, Blehert DS. Geomyces destructans sp. nov. associated with bat white-nose syndrome. Mycotaxon. 2009;108:147-54

17. Ni M, Feretzaki M, Sun S, Wang $X$, Heitman J. Sex in fungi. Annu Rev Genet. 2011:45:405-30.

18. Bennett RJ, Johnson AD. Completion of a parasexual cycle in Candida albicans by induced chromosome loss in tetraploid strains. EMBO J. 2003;22:2505-15.

19. Forche A, Alby K, Schaefer D, Johnson AD, Berman J, Bennett RJ. The parasexual cycle in Candida albicans provides an alternative pathway to meiosis for the formation of recombinant strains. PLoS Biol. 2008;6:e110.

20. Mau B, Glasner JD, Darling AE, Perna NT. Genome-wide detection and analysis of homologous recombination among sequenced strains of Escherichia coli. Genome Biol. 2006;7:R44.

21. Fitzpatrick DA. Horizontal gene transfer in fungi. FEMS Microbiol Lett. 2012;329:1-8

22. Chan CX, Beiko RG, Darling AE, Ragan MA. Lateral transfer of genes and gene fragments in prokaryotes. Genome Biol Evol. 2009;1:429-38.

23. Stanke M, Diekhans M, Baertsch R, Haussler D. Using native and syntenically mapped cDNA alignments to improve de novo gene finding. Bioinformatics. 2008;24:637-44.

24. Parra G, Bradnam K, Ning Z, Keane T, Korf I. Assessing the gene space in draft genomes. Nucleic Acids Res. 2009;37:289-97.

25. Chibucos MC, Crabtree J, Nagaraj S, Chaturvedi S, Chaturvedi V. Draft genome sequences of human pathogenic fungus Geomyces pannorum sensu Lato and Bat white nose syndrome pathogen Geomyces (Pseudogymnoascus) destructans. Genome Announc. 2013;1:e01045-13.

26. Lin Y, Smith GR. Transient, meiosis-induced expression of the rec6 and rec12 genes of Schizosaccharomyces pombe. Genetics. 1994;136:769-79.

27. Kassir Y, Granot D, Simchen G. IME1, a positive regulator gene of meiosis in S. cerevisiae. Cell. 1988;52:853-62.

28. Davis L, Barbera M, McDonnell A, Mclntyre K, Sternglanz R, Jin Q, et al. The Saccharomyces cerevisiae MUM2 gene interacts with the DNA replication machinery and is required for meiotic levels of double strand breaks. Genetics. 2001;157:1179-89.

29. Thompson EA, Roeder GS. Expression and DNA sequence of RED1, a gene required for meiosis I chromosome segregation in yeast. Mol Gen Genet MGG. 1989;218:293-301.

30. Chua PR, Roeder GS. Zip2, a meiosis-specific protein required for the initiation of chromosome synapsis. Cell. 1998;93:349-59.

31. Agarwal S, Roeder GS. Zip3 provides a link between recombination enzymes and synaptonemal complex proteins. Cell. 2000;102:245-55.

32. Briza $P$, Eckerstorfer $M$, Breitenbach $M$. The sporulation-specific enzymes encoded by the DIT1 and DIT2 genes catalyze a two-step reaction leading 
to a soluble LL-dityrosine-containing precursor of the yeast spore wall. Proc Natl Acad Sci U S A. 1994;91:4524-8.

33. Engebrecht J, Masse S, Davis L, Rose K, Kessel T. Yeast meiotic mutants proficient for the induction of ectopic recombination. Genetics. 1998;148:581-98

34. Nakayama N, Kaziro Y, Arai K, Matsumoto K. Role of STE genes in the mating factor signaling pathway mediated by GPA1 in Saccharomyces cerevisiae. Mol Cell Biol. 1988:8:3777-83.

35. Zhu YO, Siegal ML, Hall DW, Petrov DA. Precise estimates of mutation rate and spectrum in yeast. Proc Natl Acad Sci. 2014;111:E2310-8.

36. Lang Gl, Murray AW. Estimating the Per-base-pair mutation rate in the yeast saccharomyces cerevisiae. Genetics. 2008;178:67-82.

37. Hull CM, Raisner RM, Johnson AD. Evidence for mating of the "asexual" yeast Candida albicans in a mammalian host. Science. 2000;289:307-10.

38. Paoletti M, Rydholm C, Schwier EU, Anderson MJ, Szakacs G, Lutzoni F, et al. Evidence for sexuality in the opportunistic fungal pathogen Aspergillus fumigatus. Curr Biol CB. 2005;15:1242-8.

39. Muller H, Hennequin C, Gallaud J, Dujon B, Fairhead C. The asexual yeast Candida glabrata maintains distinct a and ? haploid mating types. Eukaryot Cell. 2008;7:848-58.

40. Wong S, Fares MA, Zimmermann W, Butler G, Wolfe KH. Evidence from comparative genomics for a complete sexual cycle in the "asexual" pathogenic yeast Candida glabrata. Genome Biol. 2003;4:R10.

41. Gilichinskiy DA, Khlebnikova GM, Zvyagintsev DG, Fedorov-Davydov DG, Kudryavtseva NN. Microbiology of sedimentary materials in the permafrost zone. Int Geol Rev. 1989:31:847-58.

42. Gilichinsky DA, Wilson GS, Friedmann El, McKay CP, Sletten RS, Rivkina EM, et al. Microbial populations in antarctic permafrost: biodiversity, state, age, and implication for astrobiology. Astrobiology. 2007;7:275-311.

43. Kochkina GA, Ivanushkina NE, Karasev SG, Gavrish El, Gurina LV, Evtushenko $\mathrm{LI}$, et al. Ozerskaia SM: [Micromycetes and actinobacteria under conditions of many years of natural cryopreservation]. Mikrobiologiia. 2001;70:412-20.

44. Doyle J, Doyle J. A rapid DNA isolation procedure for small quantities of fresh leaf tissue. Phytochem Bull. 1987;19:11-5.

45. Luo R, Liu B, Xie Y, Li Z, Huang W, Yuan J, et al. SOAPdenovo2: an empirically improved memory-efficient short-read de novo assembler. GigaScience. 2012;1:18

46. Schroeder A, Mueller O, Stocker S, Salowsky R, Leiber M, Gassmann M, et al. The RIN: an RNA integrity number for assigning integrity values to RNA measurements. BMC Mol Biol. 2006;7:3.

47. Kim D, Pertea G, Trapnell C, Pimentel H, Kelley R, Salzberg SL. TopHat2: accurate alignment of transcriptomes in the presence of insertions, deletions and gene fusions. Genome Biol. 2013;14:R36.

48. Harris RS. Improved pairwise alignment of genomic DNA. Ph.D. Thesis, The Pennsylvania State University. 2007.

49. Blanchette M, Kent WJ, Riemer C, Elnitski L, Smit AFA, Roskin KM, et al. Aligning multiple genomic sequences with the threaded blockset aligner. Genome Res. 2004;14:708-15.

50. Larkin MA, Blackshields G, Brown NP, Chenna R, McGettigan PA, McWilliam H, et al. Clustal W and Clustal X version 2.0. Bioinformatics. 2007;23:2947-2948,

51. Kishino $\mathrm{H}$, Hasegawa M. Evaluation of the maximum likelihood estimate of the evolutionary tree topologies from DNA sequence data, and the branching order in hominoidea. J Mol Evol. 1989;29:170-9.

52. Li H, Durbin R. Fast and accurate short read alignment with BurrowsWheeler transform. Bioinforma Oxf Engl. 2009;25:1754-60.

53. MACSE: multiple alignment of coding SEquences accounting for Frameshifts and stop codons. PLoS One. 2011;6:e22594.

54. Huson DH, Richter DC, Rausch C, Dezulian T, Franz M, Rupp R. Dendroscope: an interactive viewer for large phylogenetic trees. BMC Bioinformatics. 2007;8:460.

\section{Submit your next manuscript to BioMed Central and take full advantage of:}

- Convenient online submission

- Thorough peer review

- No space constraints or color figure charges

- Immediate publication on acceptance

- Inclusion in PubMed, CAS, Scopus and Google Scholar

- Research which is freely available for redistribution 